\title{
Modelling and Simulation of Fifty Bus System with Solar Based Multiple UPQC's
}

\author{
G. V. Prasanna Anjaneyulu*,Dr. P. Sangameswara Raju \\ EEE Department, S.V. University College of Engineering, Tirupathi, A.P., India
}

\begin{abstract}
In multi bus system, Unified Power Flow Converter (UPQC) is preferred because of the harmonic reduction ability and voltage injection property. In UPQC, PV based Boost converter is proposed to improve the Power Quality. The UPQC is used to reduce voltage sag and line losses. In this work, the authors proposed, the idea of multiple UPQC's to improve the voltage profile. Simulation studies are performed using MATLAB simulation tool. Case studies of fifty bus system with and without UPQC's are presented. The proposed system has advantages like reduced harmonic content and improved voltage profile. The simulation results are compared with theoretical results.
\end{abstract}

Keywords: Dynamic Voltage Regulator, Active Filter, Total Harmonic Distortion, Line Losses, Power Quality

\section{Introduction}

It is the objective of the electric utility to supply its customers with a sinusoidal voltage of fairly constant magnitude and frequency. The generators that produce the electric power generate a very close approximation to a sinusoidal signal. The planning, design, and operation of industrial and commercial power systems require several studies to assist in the evaluation of the initial and future system performance, system reliability, safety and the ability to grow with production and operating requirements. The conventional AC electric power systems are designed to operate with sinusoidal voltages and currents. The quality power supply is essential for proper operation of industrial processes which contain critical and sensitive loads. However nonlinear loads and electronically switched loads will distort steady state AC voltage and current waveforms.

Periodically distorted waveforms can be studied by examining the harmonic components of the waveforms. Reducing voltage and current waveform distortions to acceptable levels has been a problem in power system design from the early days of alternating current. The quality power supply is essential for proper operation of industrial processes which contain criticaland sensitive loads.

However there are loads and devices on the system which have nonlinear characteristics and result in harmonic distortion of both the voltage and current signals. As more nonlinear loads are introduced within a facility, these waveforms get more distorted. In a modern power system due to wide use of nonlinear loads such as adjustable speed drives, electric arc welders, and furnaces it has become necessary to establish criteria for limiting power quality problems. These problems cause reduction in system efficiency, poor power factor, maloperation of electronic equipment's and reduction in equipment mean life time. The nonlinear load injects the harmonic current into the networks and consequently distorts the voltage waveform. This distorted voltage waveform affects other loads connected. To avoid this problem and to protect the loads from distortion, the harmonic components of the voltage and current must be compensated. The numbers of loads which are very sensitive to PQ problems have increased in the modern power system and at the same time the number of PQ polluting factors has also escalated. The increased penetration of distributed generation sources in to the power system has further contributed to existing PQ complexities. These distributed generation sites are often fueled by renewable energy sources such as wind and solar. The random nature of these energy sources poses a reliability threat to the power system.

By use of Passive filters, the problem reduces, but these have many disadvantages such as fixed compensation, large size, and resonance problems. To overcome the above problem, the shunt active filters were used with passive filters [1]-[2], but this method does not reduce the voltage harmonics. In order to deal voltage and current harmonic problems simultaneously, the most sophisticated device i.e., unified power quality conditioner has been developed [2]-[3]. In section 2, structure of UPQC is presented. In section 3, Fifty bus system without UPQC, with UPQC and their comparative analysis are presented. Finally, section 4 concludes the results.

\section{Structure Of UPQC}

UPQC is a series combination of series and shunt active power filters sharing a common DC link. The two active power filters have different functions. Series filters is operated as a controlled voltage source to 
suppress and isolate voltage harmonics, same time shunt filters acts as a controlled current source to compensate the current harmonics.

This paper presents complete simulation of UPQC system. The basic configuration of the UPQC is presented in Figure -1.

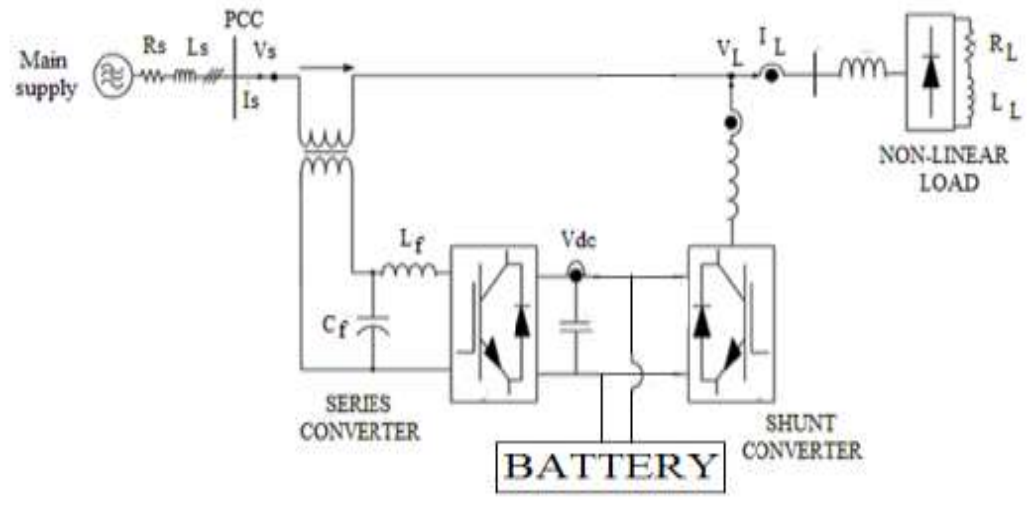

Fig.1: Basic Configuration of UPQC

Figure 1 shows a basic configuration of general UPQC consisting of two voltage source inverters: one act as a series APF and the other as shunt APF, which are connected back to back through dc link capacitor. The series APF which is connected between the source and PCC using three single phase series transformers has the capability of compensating the voltage harmonics, voltage flicker and improving voltage regulation [4]. The shunt APF is connected through a small rated capacity inductive filter in order to eliminate the high switching ripple content in the shunt APF injected current. Direct control strategy for UPQC in 3 phases, 4 wire system is given by Yong [5]. Enhancing Electric Power Quality using UPQC is given by Khadkikar [6]. Control scheme for three phase four wire UPQC in a three phase stationary frame is given by Chen [7]. Series active power filter compensates current harmonics and voltage unbalance simultaneously is given by Wallace [8]. UPQC for simultaneous voltage and current compensation is given by Ledwich [9]. Harmonic modeling of residential and commercial loads with unified power quality conditioner is given by Tulasiram [10]. Unified power quality conditioner for power quality improvement with advanced control strategy is given by Kamble, S.Y [11].

The above literature does not deal with the Power Quality Improvement in fifty bus system using UPQC. This work proposes multiple UPQC in fifty bus systemfor improving Power Quality. A new Simulink model for fifty bus system with UPQC is presented in this paper. In the present work, power quality in fifty bus system is improved using UPQC. The UPQC is connected near non linear load.

\section{Simulation Results}

Fifty bus system without UPQC are shown in Figure 3.1. Each line is shown as series impedance. Each load is shown as shunt impedance. Each alternator is shown as a AC source. The voltage at bus 4 is shown in Figure 3.2. The peak value of voltage is $0.9 * 10^{4}$ real and reactive power are $2.8 * 10^{5} \mathrm{~W}$ and $8 * 10^{4} \mathrm{VAR}$ respectively.

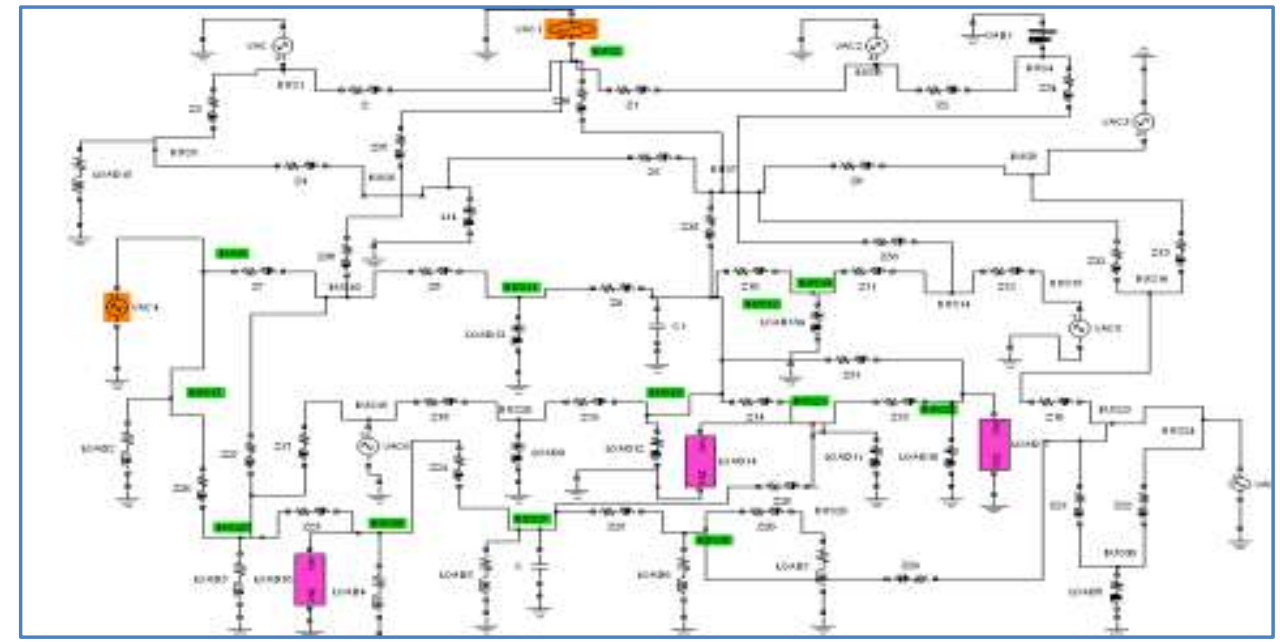

Fig.3.1: Fifty Bus Systems without UPQC 


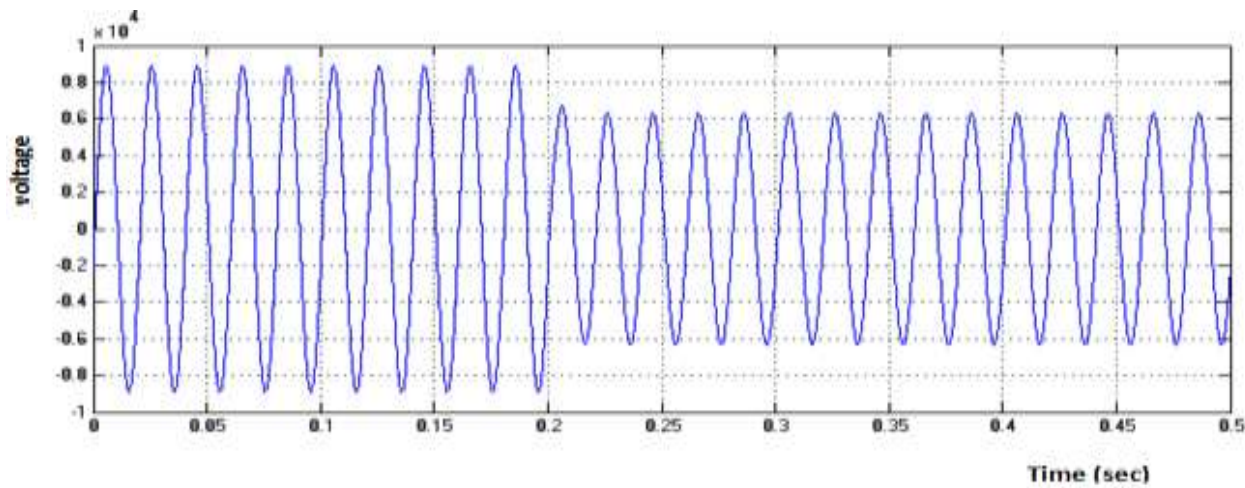

Fig.3.2: Voltage at Bus -4

The Real power at Bus four is shown in Figure 3.3. The Reactive power at Bus four is shown in Figure 3.4. Real and Reactive power decreases to $1.4 * 10^{5} \mathrm{~W}$ and $4 * 10^{4}$ VAR respectively.

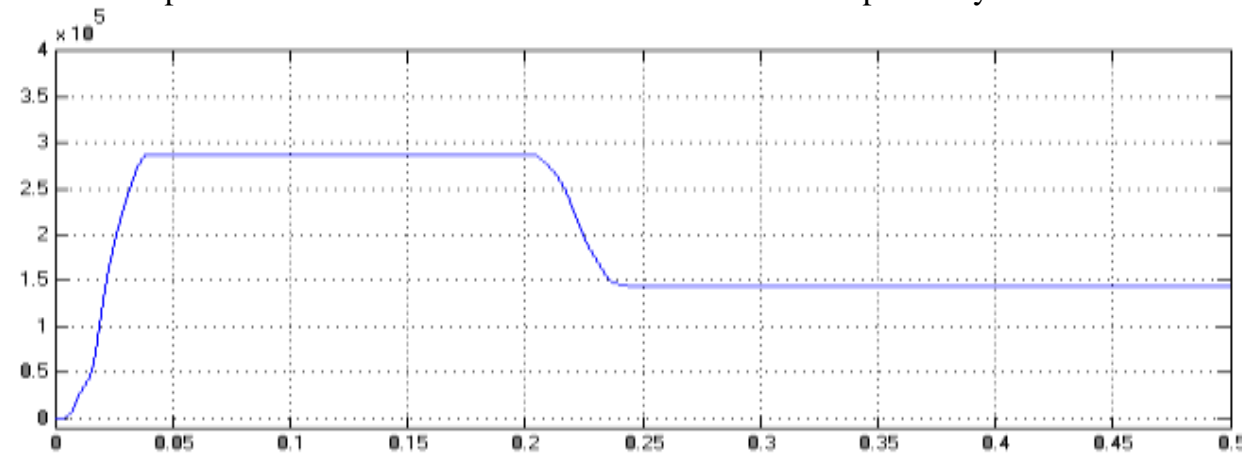

Fig.3.3: Real Power at Bus -4

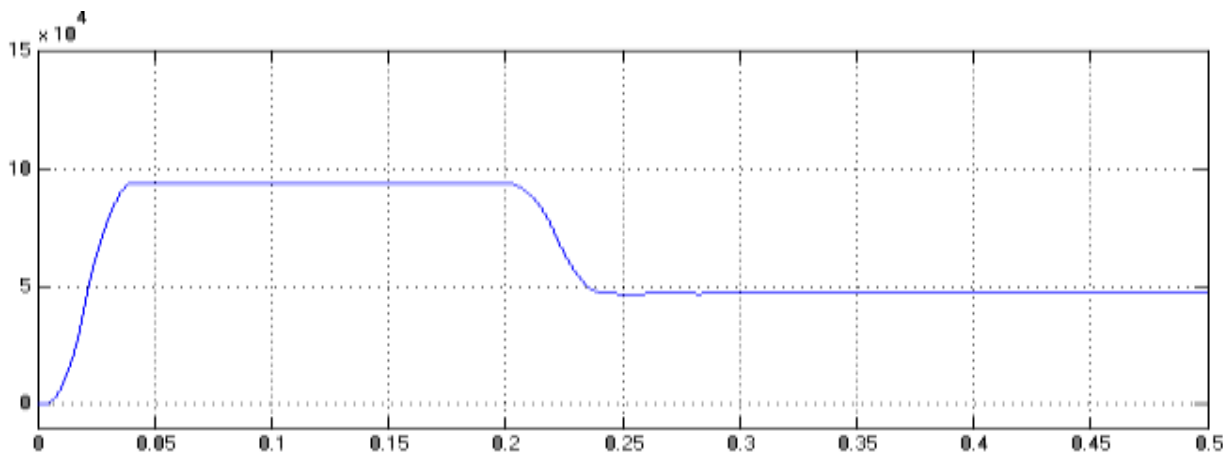

Fig.3.4: Reactive Power at Bus -4

Frequency spectrum of 50 bus system without UPQC is shown in Figure 3.5 and T.H.D content is 14.2\%.

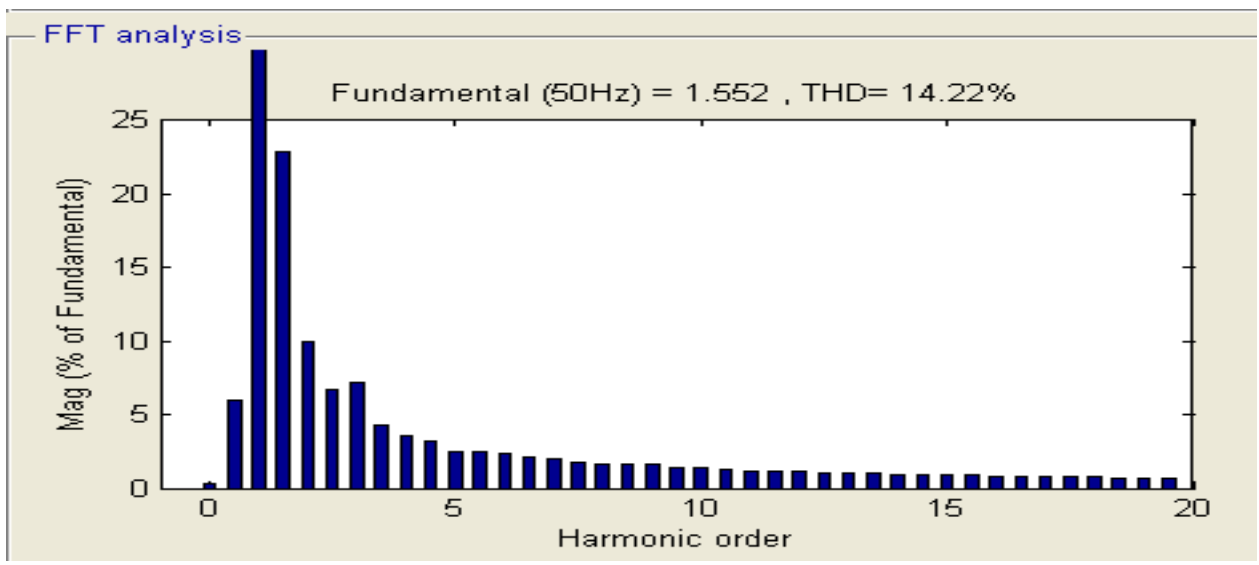

Fig.3.5: Frequency Spectrum without UPQC 
The Fifty bus system with UPQC is shown in Figure 3.6. Three UPQCs are introduced. The UPQC model is shown in Figure 3.7. The peak value of voltage is $7000 \mathrm{~V}$, real and reactive powers are $2.4 * 10^{5} \mathrm{~W}$ and $7.5 * 10^{4}$ VAR respectively.

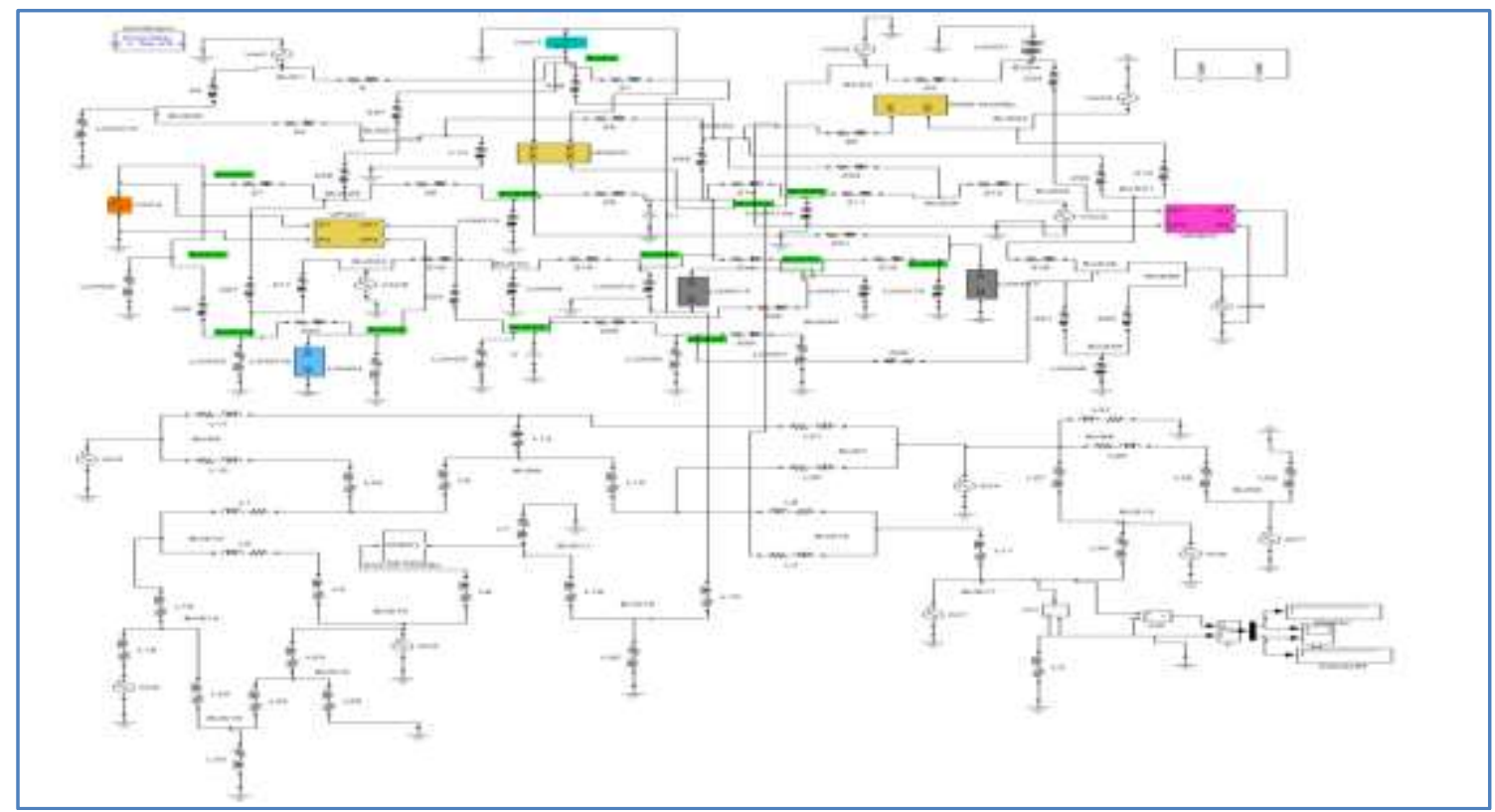

Fig.3.6: Fifty Bus System with UPQC

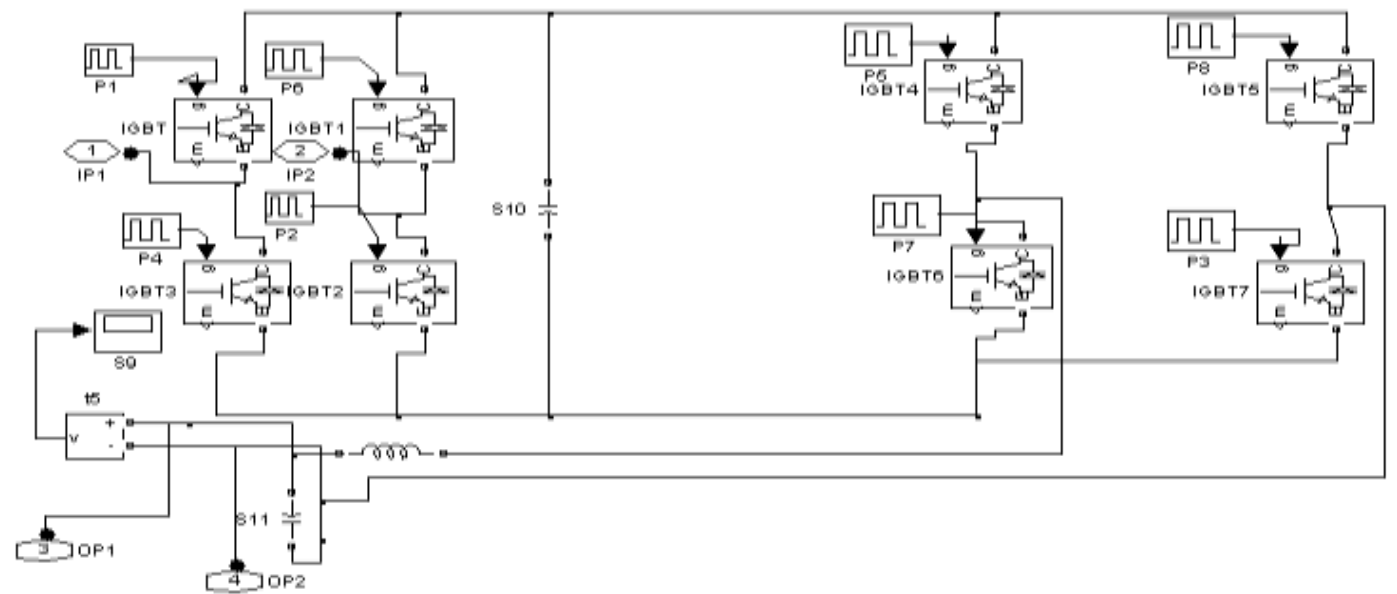

Fig.3.7: Model for UPQC

The Voltage of bus four is shown in Figure 3.8. The Real power at bus four is shown in Figure 3.9. The Reactive power at bus four is shown in Figure 3.10. Real and reactive power decreases to $1.8^{*} 10^{5} \mathrm{~W}$ and $5.8 * 10^{4} \mathrm{VAR}$.

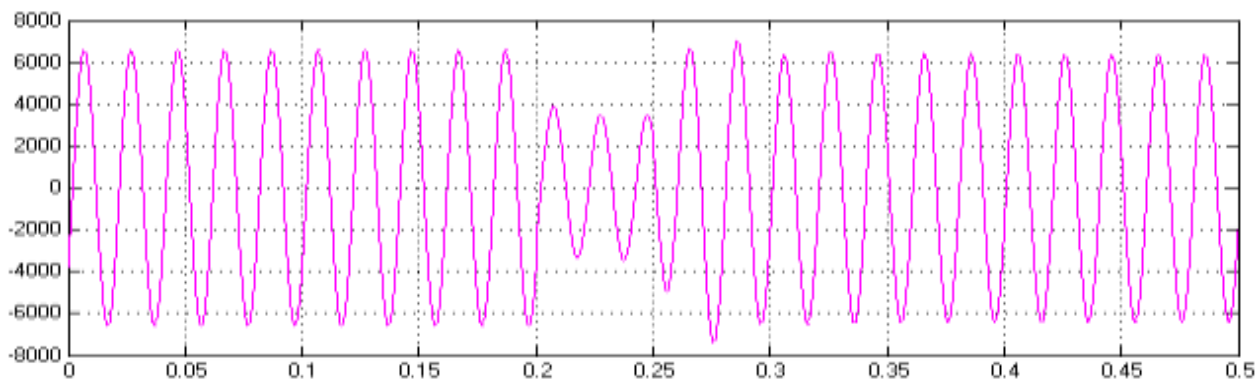

Fig.3.8: Voltage at Bus -4 




Fig.3.9: Real Power at Bus -4

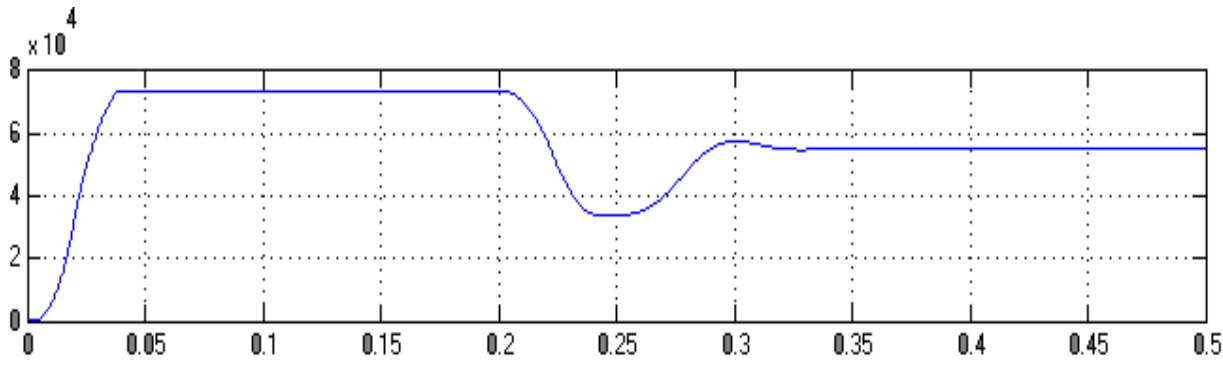

Fig.3.10: Reactive Power at Bus -4

The solar system with Boost Converter is shown in Figure 3.11. The Output voltage of PV system is boosted using a step up converter. The output of step up converter is inverted and it is filtered using LC filter. The solar model is shown in Figure 3.12. The output power is obtained as product of output voltage and current.

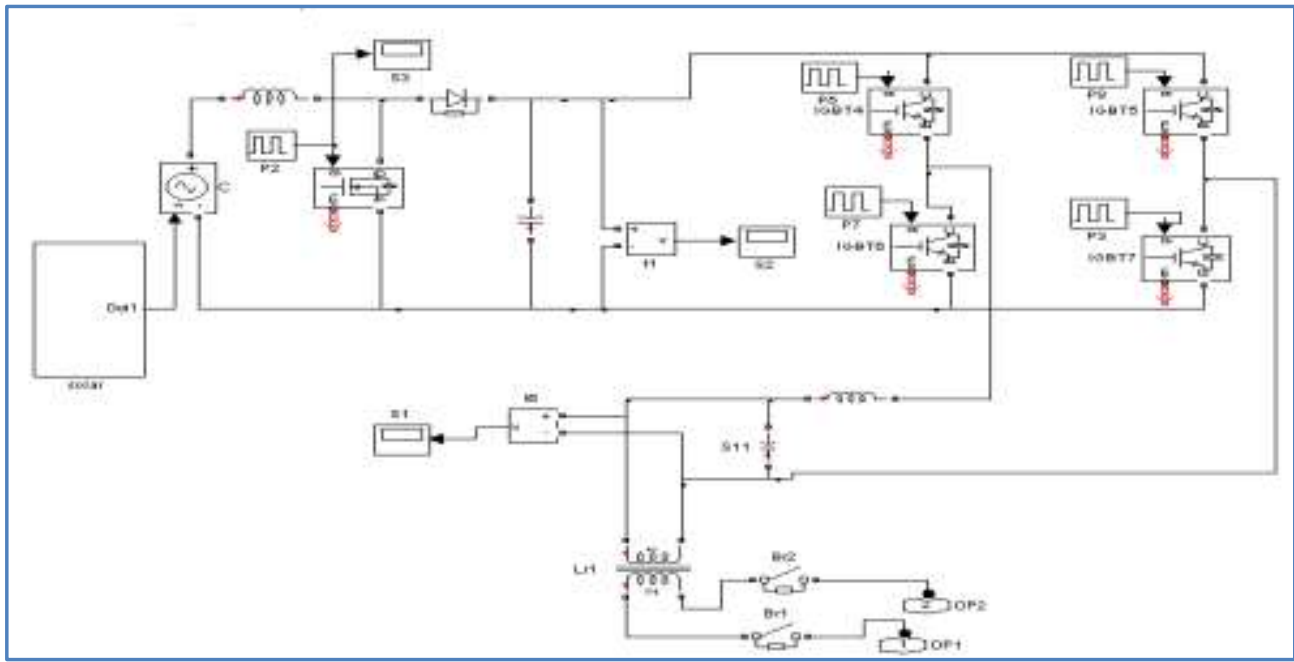

Fig.3.11: SOLAR with Boost Converter

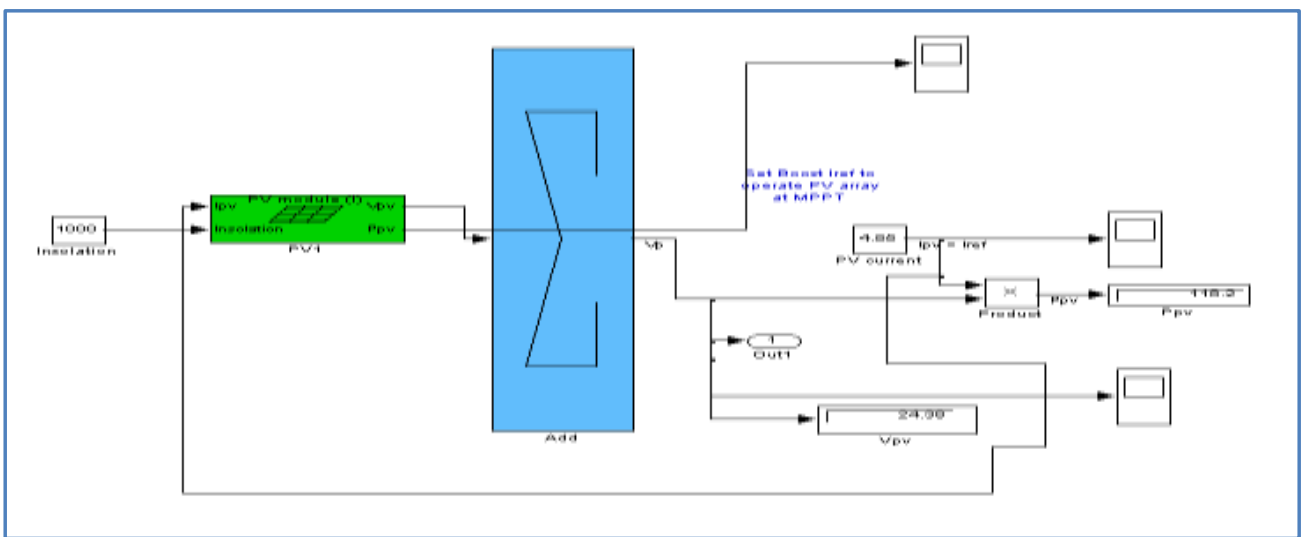

Fig.3.12: SOLAR Model 
The Output Voltage of Solar Array is shown in Figure 3.13. The Output Voltage of Boost Converter shown in Figure 3.14. The peak value of voltage is $24.4 \mathrm{~V}$, which from solar array output voltage. The peak value output voltage of boost converter is $60 \mathrm{~V}$.

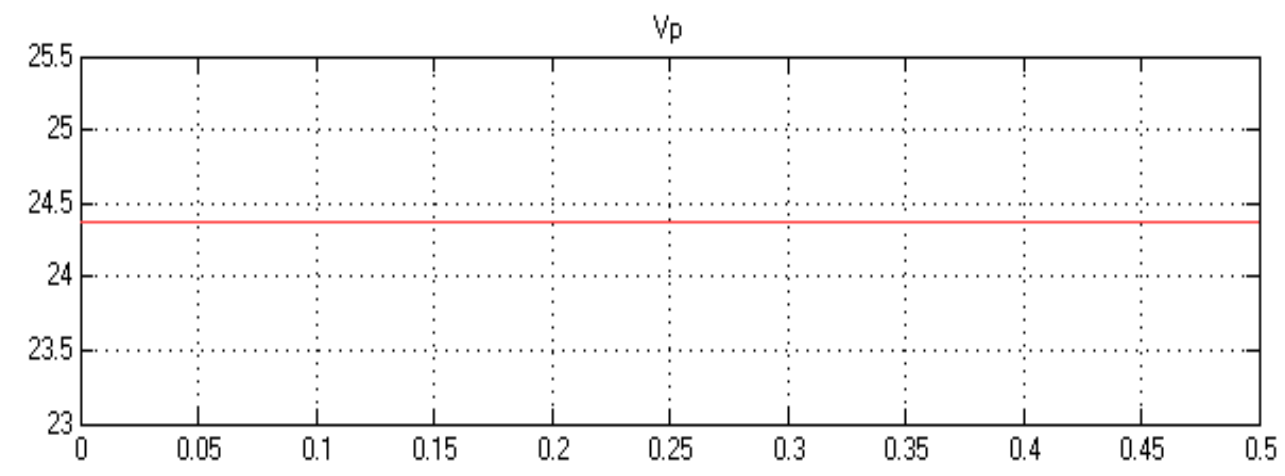

Fig.3.13: Output Voltage of Solar Array

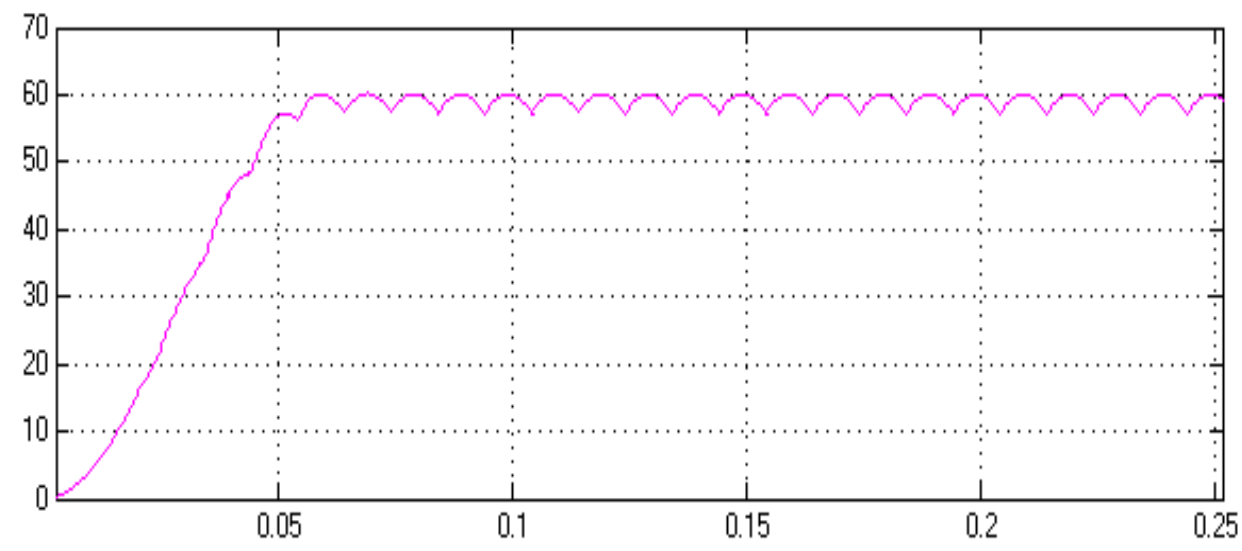

Fig.3.14: Output Voltage of Boost Converter

The frequency spectrum is shown in Figure 3.15 and T.H.D content is $3.2 \%$

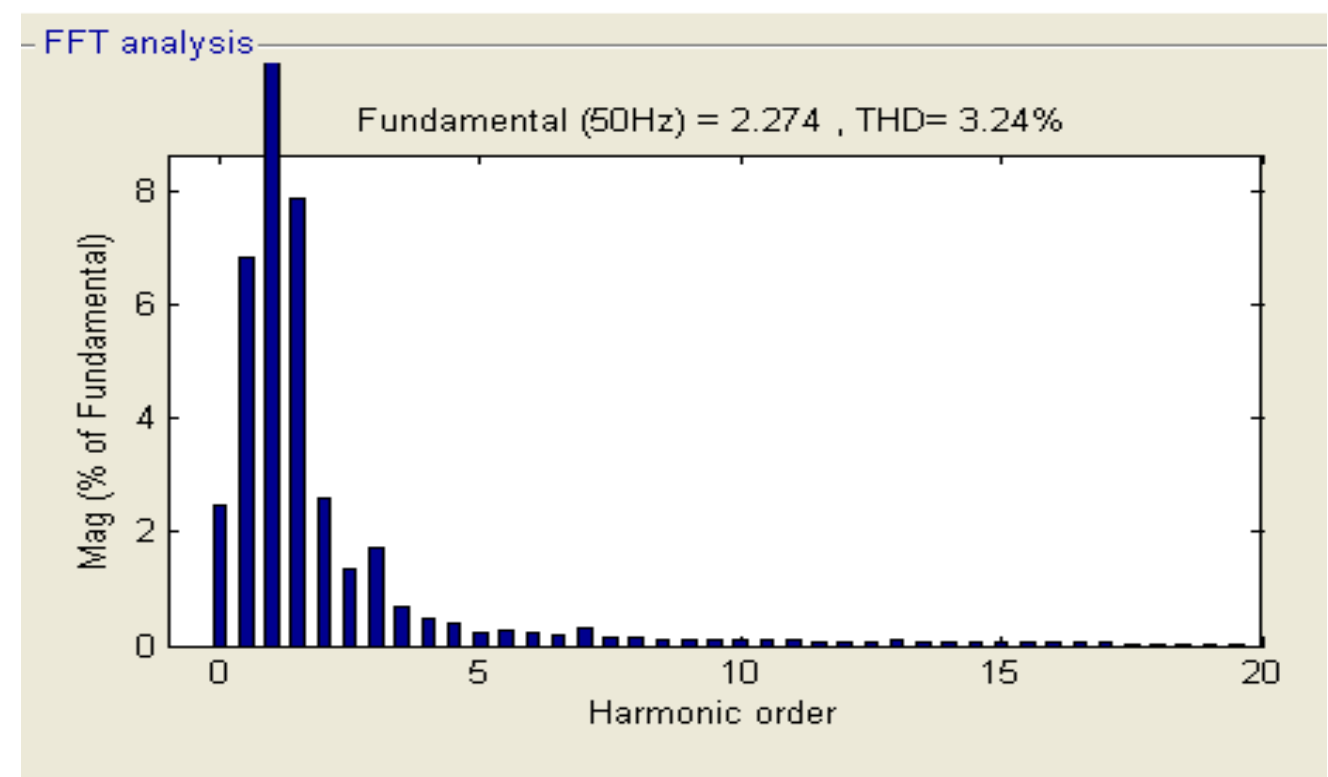

Fig. 3.15: Spectrum with UPQC

The real and reactive power losses at various buses without and with UPQC are presented in the following Table 3.1. The increase in real and reactive power is due to increase in the voltage. 
Modelling And Simulation Of Fifty Bus System With Solar Based Multiple UPQC's

Table 3.1: Real \& Reactive power without\& with UPQC

\begin{tabular}{|c|c|c|c|c|}
\hline BUS NO & $\begin{array}{lr}\text { REAL } & \text { POWER } \\
\text { WITHOUT UPQC } & (\mathrm{MW}) \\
\end{array}$ & $\begin{array}{l}\text { REAL POWER } \\
\text { WITH UPQC }(\mathrm{MW})\end{array}$ & $\begin{array}{lc}\text { REACTIVE } & \text { POWER } \\
\text { WITHOUT UPQC (MVAR) }\end{array}$ & $\begin{array}{ll}\text { REACTIVE } & \text { POWER } \\
\text { WITH UPQC (MVAR) }\end{array}$ \\
\hline BUS-1 & 0.277 & 0.275 & 0.304 & 0.352 \\
\hline BUS-2 & 0.263 & 0.272 & 0.301 & 0.348 \\
\hline BUS-3 & 0.420 & 0.575 & 1.320 & 1.801 \\
\hline BUS-4 & 0.378 & 2.431 & 2.210 & 2.788 \\
\hline BUS-5 & 0.321 & 0.442 & 2.230 & 2.791 \\
\hline BUS-6 & 0.311 & 0.378 & 2.270 & 2.810 \\
\hline BUS-7 & 0.321 & 0.358 & 2.260 & 2.842 \\
\hline BUS-8 & 0.318 & 0.346 & 2.241 & 2.846 \\
\hline BUS-9 & 0.309 & 0.336 & 2.238 & 2.832 \\
\hline BUS-10 & 0.356 & 0.373 & 2.861 & 2.989 \\
\hline BUS-11 & 3.200 & 3.210 & 3.350 & 3.360 \\
\hline BUS-12 & 3.110 & 3.120 & 3.230 & 3.250 \\
\hline BUS-13 & 2.130 & 2.180 & 2.290 & 2.280 \\
\hline BUS-14 & 1.890 & 1.982 & 1.971 & 1.998 \\
\hline BUS-15 & 1.250 & 1.450 & 1.380 & 1.570 \\
\hline BUS-16 & 1.069 & 1.760 & 1.860 & 1.890 \\
\hline BUS-17 & 1.089 & 2.087 & 2.879 & 2.978 \\
\hline BUS-18 & 1.068 & 2.042 & 2.798 & 2.861 \\
\hline BUS-19 & 1.863 & 2.456 & 2.388 & 2.458 \\
\hline BUS-20 & 1.861 & 2.452 & 2.386 & 2.451 \\
\hline BUS-21 & 0.378 & 2.431 & 2.210 & 2.788 \\
\hline BUS-22 & 3.260 & 3.351 & 3.612 & 3.629 \\
\hline BUS-23 & 1.089 & 2.087 & 2.879 & 2.978 \\
\hline BUS-24 & 1.890 & 1.982 & 1.971 & 1.998 \\
\hline BUS-25 & 2.891 & 2.958 & 3.121 & 3.221 \\
\hline BUS-26 & 2.812 & 2.859 & 2.843 & 2.856 \\
\hline BUS-27 & 0.420 & 0.575 & 1.320 & 1.801 \\
\hline BUS-29 & 3.200 & 3.210 & 3.350 & 3.360 \\
\hline BUS-30 & 0.378 & 2.431 & 2.210 & 2.788 \\
\hline BUS-31 & 0.321 & 0.442 & 2.230 & 2.791 \\
\hline BUS-32 & 0.311 & 0.378 & 2.270 & 2.810 \\
\hline BUS-33 & 0.321 & 0.358 & 2.260 & 2.842 \\
\hline BUS-34 & 0.318 & 0.346 & 2.241 & 2.846 \\
\hline BUS-35 & 1.890 & 1.982 & 1.971 & 1.998 \\
\hline BUS-36 & 0.420 & 0.575 & 1.320 & 1.801 \\
\hline BUS-37 & 0.311 & 0.378 & 2.270 & 2.810 \\
\hline BUS-38 & 0.321 & 0.358 & 2.260 & 2.842 \\
\hline BUS-39 & 0.318 & 0.346 & 2.241 & 2.846 \\
\hline BUS-40 & 0.309 & 0.336 & 2.238 & 2.832 \\
\hline BUS-41 & 0.356 & 0.373 & 2.861 & 2.989 \\
\hline BUS-42 & 3.200 & 3.210 & 3.350 & 3.360 \\
\hline BUS-43 & 3.110 & 3.120 & 3.230 & 3.250 \\
\hline BUS-44 & 2.130 & 2.180 & 2.290 & 2.280 \\
\hline BUS-45 & 1.890 & 1.982 & 1.971 & 1.998 \\
\hline BUS-46 & 1.250 & 1.450 & 1.380 & 1.570 \\
\hline BUS-47 & 1.069 & 1.760 & 1.860 & 1.890 \\
\hline BUS-48 & 1.089 & 2.087 & 2.879 & 2.978 \\
\hline BUS-49 & 1.580 & 2.560 & 2.980 & 2.970 \\
\hline BUS-50 & 1.681 & 2.781 & 2.890 & 2.987 \\
\hline
\end{tabular}

\section{Conclusions}

In this paper, the proposed PV boost converter based UPQC system was presented. Simulation results with and without UPQC was performed using MATLAB. The results indicated that performance of fifty bus system with UPQC is superior that of the system without UPQC. The simulation studies indicated that the real power increases by about $5 \%$ and reactive power increases by $13 \%$ after adding UPQC. The disadvantage of UPQC is that it requires two inverters, PV array and Boost converter. By considering the performance of UPQC, it is more suitable for multibus systems.

The investigations of fifty bus system with single boost converter based PV system were carried out. The comparison of single boost system with two inductor boost converter system with be done future. The closed loop control system using fuzzy logic controller be done in near future.

\section{References}

[1]. H. Akagi, "New trends in active filters for power conditioning," IEEE Trans. Ind. Applicat., vol. 32, pp. 1312-1332, Nov/Dec. 1996.

[2]. H. Akagi, E. H. Watanabe, and M. Aredes, "Instantaneous power theory and applications to power conditioning," Hoboken, NJ: Wiley IEEE Press, Apr. 2007. 
[3]. H. Fujita and H. Akagi, "The unified power quality conditioner: The integration of series and shunt active filters," IEEE Trans. Power Electron., vol. 13, no. 2, pp. 315-322, Mar. 1998.

[4]. Teke, L. Saribulut and M. Tumay, “ A novel reference signal generation method for power quality improvement of unified power quality conditioner,” IEEE Trans. Power Del., Vol. 26, no. 4, pp. 2205-2214, Oct. 2011.

[5]. Tan Zhili, Li Xun, Chen Jian, Kang Yong and DuanShanxu, "A direct control strategy for UPQC in three-phase four-wire system," Proc. IEEE Conf. on Power Electronics and Motion Control 2006, vol. 2, pp. 1-5.

[6]. V. Khadkikar, "Enhancing Electric Power Quality Using UPQC: A comprehensive overview," IEEE Trans, Power Electron. Vol. 27, No. 5. Pp. 2284 - 2297, May 2012.

[7]. Li. Xun, Zhu. Guorong, DuanShanxuand Chen Jian Chen, "Control scheme for three-phase four wire UPQC in a three-phase stationary frame,” Procd. IEEE/IECON 2007, pp. 1732-1736, 2007.

[8]. L. Moran, I. Pastonini, J. Dixon and R. Wallace, "Series active power filter compensates current harmonics and voltage unbalance simultaneously," Proc. IEE Gener., Trans. and Distrb., Vol. 147, No.1, pp. 31-36, Jan 2000.

[9]. A. Ghosh and G. Ledwich, "A unified power quality conditioner (UPQC) for simultaneous voltage and current compensation," Elect. Power Syst. Res., pp. 55-63, 2001.

[10]. R. Kameswara Rao and S.S. Tulasiram, "Harmonic modeling of residential and commercial loads with unified power quality conditioner," International journal of scientific \& engineering research, vol. 3, issue 6, June-2012 1, ISSN 2229-5518.

[11]. V. Khadkikar and A. Chandra, "UPQC-S: A novel concept of simultaneous voltage sag/swell and load reactive power compensations utilizing series inverter of UPQC," IEEE Trans. Power Electron., vol. 26, no. 9, pp. 2414-2425, Sep. 2011.

[12]. Kamble, S.Y., Waware, M.M. "Unified power quality conditioner for power quality improvement with advanced control strategy" IEEE International Multi Conference on Automation, Computing, Control, Communication and Compressed Sensing on 22-23 March 2013, pp. 432 - 437, 22-23 March 2013. 